\title{
Variation of sperm morphology in Pacific oyster precludes its use as a species marker but enables intraspecific geo-authentification and aquatic monitoring
}

\author{
Arkadiy Reunov ${ }^{1,2^{*}}$, Evgenia Vekhova ${ }^{2}$, Evgeny Zakharov ${ }^{3}$, Yulia Reunova ${ }^{2}$, Yana Alexandrova $^{2}$, \\ Svetlana Sharina ${ }^{2,4}$ and Andrey Adrianov ${ }^{2,4}$
}

\begin{abstract}
According to recent reports, shell morphology is unreliable for the identification of oysters because of the high phenotypic plasticity of these bivalves. Using COI DNA barcoding and sperm morphology, we reinvestigated the species validity of wild Pacific oyster Crassostrea gigas habituating the Peter the Great Bay (Sea of Japan). DNA barcoding confirmed the species validity of samples collected. Application of the single sperm pattern was not possible for species identification due to pronounced sperm plasticity being found. Six sperm morphs were discovered in the testes of each oyster collected. The amount of abundant sperm morphs and the type of the most dominant sperm pattern are particular to geographical localities that are individual depending on the environmental factors. Ecological monitoring of marine areas and commercially assigned intraspecific geo-authentification of the Pacific oyster seems possible based on the analysis of this species' heterogenic sperm. Further work will be needed to test if sperm heterogeneity exists in other Ostreidae species and if heterogenic sperms could be used for interspecific analysis.
\end{abstract}

Keywords: Pacific Ocean, Sea of Japan, Crassostrea gigas, DNA barcoding, COI, Sperm

\section{Introduction}

The Pacific shore in the far eastern region of Russia (Primorye) is a habitat for the wild Pacific oyster that is not an object of commercial fishing and represents a natural reserve of this commercially valuable bivalve mollusc. This oyster has been identified as Crassostrea gigas based on shell morphology [1-3]. However, shell appearance is not a reliable feature for oyster identification because of high phenotypic plasticity in these bivalves $[4,5]$. Taking into account that the validity of $C$. gigas has never been genetically confirmed in Primorye, the genetic analysis of specimens seems necessary. According to Will et al. [6], the most valid identification of species must be conducted by integrative taxonomy using a combination of

\footnotetext{
*Correspondence: areunov@ottawaheart.ca

${ }^{1}$ Electron Microscopy Laboratory, University of Ottawa Heart Institute, 40 Ruskin St., Ottawa, ON K1Y 4W7, Canada

Full list of author information is available at the end of the article
}

both genetic data and morphological feature. Thus, a reliable morphological trait is needed. Considering that in some cases the sperm structure is used for bivalve mollusc identification [7], it seems reasonable to investigate if the morphology of spermatozoa could be used as a feature for the identification of the Pacific oysters in Primorye.

During this work, we aimed to test if sperm morphology is specific enough to be used as a taxonomically significant feature for Pacific oyster identification in Primorye. Using COI DNA barcoding that is assigned as most convenient for species validity identification [8], and proven for successful discrimination of other oyster species [9], we also aimed to determine if the samples collected belong to C. gigas.

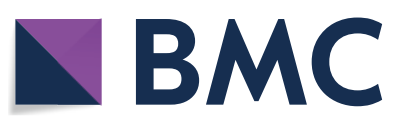

(c) The Author(s) 2018. This article is distributed under the terms of the Creative Commons Attribution 4.0 International License (http://creativecommons.org/licenses/by/4.0/), which permits unrestricted use, distribution, and reproduction in any medium, provided you give appropriate credit to the original author(s) and the source, provide a link to the Creative Commons license, and indicate if changes were made. 


\section{Materials and methods}

\section{Specimen collection}

Living specimens of the Pacific oyster Crassostrea gigas (Thunberg, 1793) were collected in 2015. The end of July was chosen for collection because it is a period of natural spawning of oysters in Primorye. Four geographic localities were chosen for sampling (Fig. 1). 1-location in the Amursky Bay (the Peter the Great Bay, Sea of Japan, Russia, $\left.43^{\circ} 14^{\prime} 27.69^{\prime \prime} \mathrm{N}, 131^{\circ} 89^{\prime} 72.60^{\prime \prime} \mathrm{E}\right)$. 2-location in the Eastern Bosphorus Strait (the Peter the Great Bay, Sea of Japan, Russia, 43 $\left.07^{\prime} 32.14^{\prime \prime} \mathrm{N}, 131^{\circ} 84^{\prime} 34.27^{\prime \prime} \mathrm{E}\right)$; 3-location in the Ussuriisky Bay (the Peter the Great Bay, Sea of Japan, Russia, $\left.43^{\circ} 18^{\prime} 83.65^{\prime \prime} \mathrm{N}, 132^{\circ} 11^{\prime} 23.44^{\prime \prime} \mathrm{E}\right)$; $4-$ location in the Vostok Bay (the Peter the Great Bay, Sea of Japan, Russia, $\left.42^{\circ} 89^{\prime} 32.45^{\prime \prime} \mathrm{N}, 132^{\circ} 73^{\prime} 47.65^{\prime \prime} \mathrm{E}\right)$. Three males from each location were selected for both the genetic analysis and study of male gametes.

\section{Genetic analysis}

Specimens were deposited at the Canadian Centre for DNA Barcoding, Biodiversity Institute of Ontario (University of Guelph, Canada) with the following catalogue numbers: YARRA063-12, YARRA064-12, YARRA06512 (Amursky Bay, Sea of Japan, Russia); YARRA06612, YARRA067-12, YARRA068-12 (Eastern Bosporus Strait, Sea of Japan, Russia); YARRA069-12, YARRA07012, YARRA (Ussuriisky Bay, Sea of Japan, Russia); YARRA060-12, YARRA061-12, YARRA062-12 (Vostok Bay, Sea of Japan, Russia).
Total DNA was extracted from pieces of mantle $\left(3-5 \mathrm{~mm}^{3}\right)$ according to a standard phenol/chlorophorm extraction method [10]. Partial sequences of mitochondrial cytochrome $c$ oxidase subunit I gene (COI) were amplified and sequenced using the universal invertebrate primer pairs: LCO1490-5'-GGTCAACAAATCATA AAGATATTGG-3' and HCO2198-5'-TAAACTTCA GGGTGACCAAAAAATCA-3' [11].

PCR amplification was performed in a $25 \mu \mathrm{l}$ reaction volume containing $17.4 \mu \mathrm{l}$ of water; $2.5 \mu \mathrm{l}$ of $10 \times$ buffer (Evrogen); $2.0 \mu \mathrm{l}$ of dNTP (concentration $2.5 \mathrm{mM}$ of each, Evrogen); $1 \mu \mathrm{l}$ of each forward and reverse PCR primer $(5 \mathrm{pmol} / \mu \mathrm{l}) ; 0.1 \mu \mathrm{l}$ of Taq DNA polymerase $(5$ units $/ \mu \mathrm{l}$, Evrogen); and $1 \mu \mathrm{l}$ of template DNA solution. The cycling parameters were an initial denaturation step at $94{ }^{\circ} \mathrm{C}$ ( $3 \mathrm{~min}$ ), followed by 30 cycles of denaturation for $45 \mathrm{~s}$ at $94{ }^{\circ} \mathrm{C}$, annealing for $90 \mathrm{~s}$ at $42^{\circ} \mathrm{C}$, and extension for $120 \mathrm{~s}$ at $72{ }^{\circ} \mathrm{C}$; and a final extension phase at $72{ }^{\circ} \mathrm{C}$ for $5 \mathrm{~min}$.

Amplification products were applied as templates for sequencing, using the same primers as for PCR and "Big Dye Terminator Cycle Sequencing Kit" v. 3.1 (Applied Biosystems, USA) following the manufacturer's protocol. The cycling parameters were an initial denaturation step at $96{ }^{\circ} \mathrm{C}(1 \mathrm{~min})$, followed by 25 cycles of $10 \mathrm{~s}$ at $96{ }^{\circ} \mathrm{C}$, $10 \mathrm{~s}$ at $42-49^{\circ} \mathrm{C}$ and $4 \mathrm{~min}$ at $60^{\circ} \mathrm{C}$. Sequencing reaction products were purified by ethanol precipitation and analysed on an ABI-3130 Genetic Analyzer (Applied Biosystems, ABI, USA). Sequences were verified by forward and reverse comparisons.

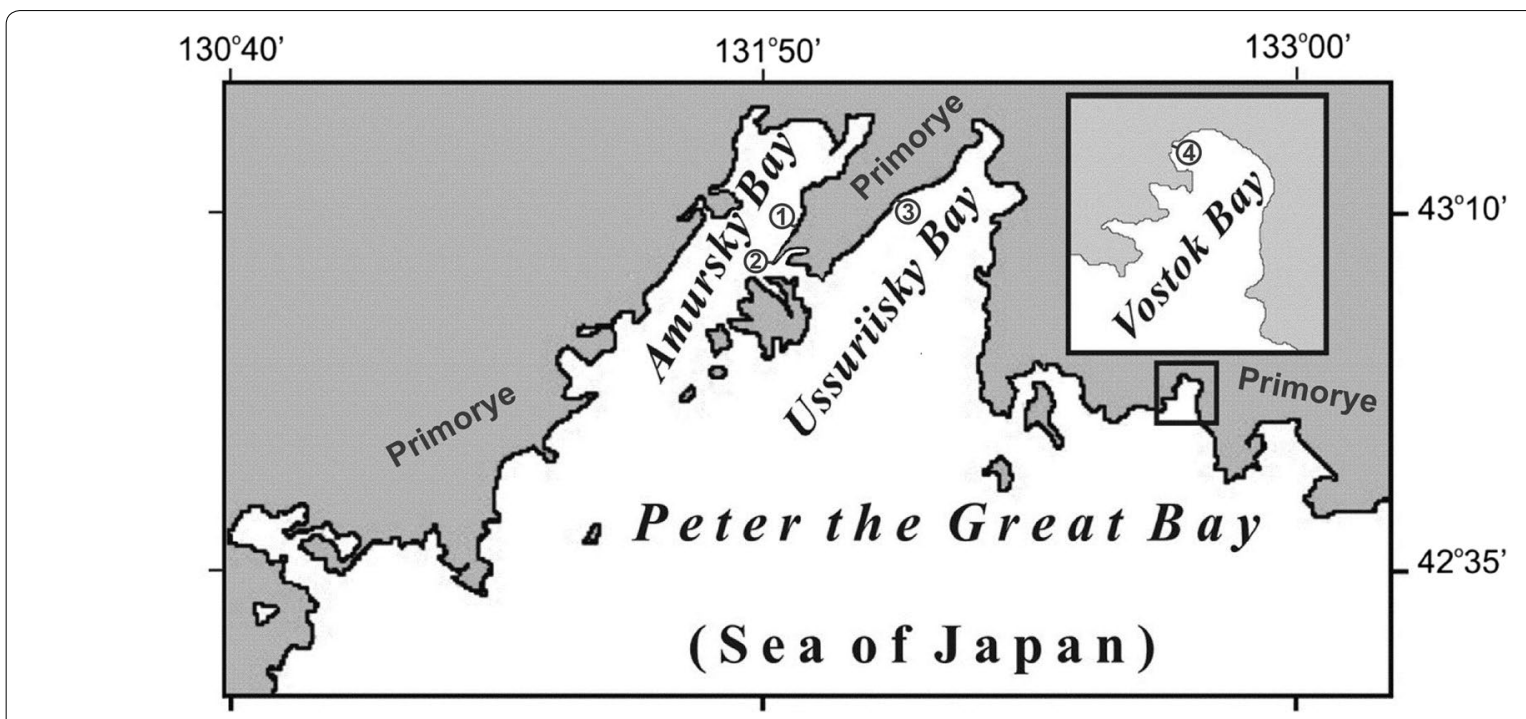

Fig. 1 Pacific oyster Crassostrea gigas. The map showing the geographic locations of specimens collected in Primorye. 1-location in the Amursky

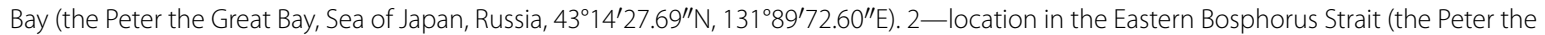

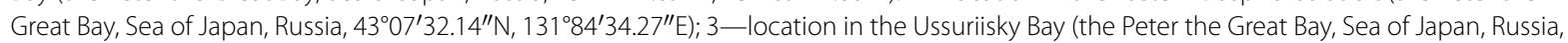
$\left.43^{\circ} 18^{\prime} 83.65^{\prime \prime} \mathrm{N}, 132^{\circ} 11^{\prime} 23.44^{\prime \prime} \mathrm{E}\right) ; 4$ - location in the Vostok Bay (the Peter the Great Bay, Sea of Japan, Russia, 42 $89^{\prime} 32.45^{\prime \prime} \mathrm{N}, 132^{\circ} 73^{\prime} 47.65^{\prime \prime} \mathrm{E}$ ) 
The contigs were obtained and edited using ChromasPro v. 1.7.6 (http://www.technelysium.com.au/ chromas.html). Eleven sequences, $658 \mathrm{bp}$ in length, were obtained. All sequences and their metadata determined in this study have been deposited in the BOLD database (Barcode of Life Data System) (http://boldsystems.prg) under accession numbers YARRA060-12|RRYA-60YARRA070|RRYA-70. Our dataset was compared with the sequences of $C$. gigas from GenBank (NCBI, http://www.ncbi.nlm.nih.gov/) and BOLD. Sequences of two species from the genus Crassostrea (C. virginica (EU007485) and C. sikamea (AY632568)) were selected as the outgroup.

Sequences were aligned using MUSCLE [12] implemented in the program MEGA 5 [13]. MEGA 5 was also used to calculate pairwise genetic distances ( $p$ distances) and to build trees. Kimura's two-parameter model (K2P) [14] was used for estimation of intraspecific and interspecific distances and constructed neighbor-joining (NJ) trees. All estimations of sequences and distances were performed excluding the outgroup. Bootstrap analysis with 1000 replications was used to assess the stability of each node.

\section{Transmission electron microscopy (TEM)}

Male gonads were dissected, cut into small pieces and fixed overnight in primary fixative containing $2.5 \%$ glutaraldehyde in $0.1 \mathrm{M}$ cacodylate buffer $(\mathrm{pH} 7.4)$ with osmolarity $1100 \mathrm{mOsm}$ adjusted by sodium chloride. Fixed tissues were washed in buffer, postfixed in $2 \% \mathrm{OsO}_{4}$ in sea water, rinsed in $0.1 \mathrm{M}$ cacodylate buffer and distilled water, dehydrated in an ethanol series, infiltrated and embedded in Spurr's resin. Ultra-thin sections were mounted on slot grids that were coated with formvar film stabilised with carbon. Sections were stained with $2 \%$ alcoholic uranyl acetate and Reynolds lead citrate and were examined with a transmission electron microscope Zeiss Libra 120.

\section{Scanning electron microscopy (SEM)}

Males were identified by study of spawned suspension using light microscopy. Sperm suspension was collected during natural spawning induced by a temperature increase, pipetted onto a Thermanox coverslip (Cat. \#72280) and allowed to settle for $5 \mathrm{~min}$. Coverslips with attached sperm cells were fixed overnight in $2.5 \%$ glutaraldehyde in $0.1 \mathrm{M}$ cacodylate buffer, $(\mathrm{pH}$ 7.4) with osmolarity 1100 mOsm adjusted with sodium chloride. Primary fixed materials were washed in $0.1 \mathrm{M}$ cacodylate buffer $(\mathrm{pH} 7.4)$ and postfixed in $1 \% \mathrm{OsO}_{4}$ in sea water. After the following washing in buffer, the samples were rinsed in distilled water, dehydrated in a graded series of ethanol solutions, transferred to acetone and critical-point dried in $\mathrm{CO}_{2}$. Dried materials were mounted onto aluminum stubs, coated with gold, and examined with a scanning electron microscope LEO-430.

\section{Quantitative analysis}

The quantification of sperm morphology patterns was done for the oysters with catalogue numbers YARRA06312, YARRA064-12, YARRA065-12 (Amursky Bay, Sea of Japan, Russia); YARRA066-12, YARRA06712, YARRA068-12 (Eastern Bosporus Strait, Sea of Japan, Russia), YARRA069-12, YARRA070-12, YARRA (Ussuriisky Bay, Sea of Japan, Russia); YARRA060-12, YARRA061-12, YARRA062-12 (Vostok Bay, Sea of Japan, Russia). For each sample, 100 sperm cells were considered, thus 300 cells were studied for each location, and 1200 sperms were investigated altogether. Sperm patterns were identified by scanning electron microscopy and the frequency of each pattern was calculated. All values are expressed as means with standard error of the mean (SEM). Differences between groups were calculated using Student's $t$ test. $P<0.05$ was considered statistically significant.

\section{Results}

Identification of C. gigas species validity by analysis of $\mathrm{COI}$ gene

During our analysis, the phylogenetic trees were built using sequences obtained for our samples and sequences that were chosen for current study from the GenBank database (NCBI) (Figs. 2, 3). These trees show that all sequences of $C$. gigas are split into two clades (clade I-100 and $92 \%$ and clade II-95 and 84\%) with high bootstrap support (100\% for first dataset and $99 \%$ for the second).

The average pairwise distance ( $p$ distance) between two clades is $2.64 \pm 0.02 \%$ (mean \pm standard deviation) for the first dataset $(3.103 \pm 0.02 \%$ for second dataset), while interspecific divergence within clade $\mathrm{I}$ is $0.2 \pm 0.01 \%$ $(0.47 \% \pm 3.557 \mathrm{e}-005)$, and within clade $\mathrm{II}-0.31 \pm 0.06 \%$ $(0.39 \pm 0.19 \%)$. Thus, there is a "barcoding gap" [15] between the clades and, based on the $10 \times$-rule [8], we conclude that specimens of clade II (EU007512, EU007510, EU007507) may not belong to C. gigas.

Using BLAST (Basic Local Alignment Search Tool, NCBI; http://blast.ncbi.nlm.nih.gov/Blast.cgi), we compared sequences of EU007512, EU007510, EU007507 with other sequences from GenBank. These sequences showed more identity with sequences of $C$. angulata (Ident 99\%, for the first dataset and 100\% for the second), than with C. gigas (Ident 98 and $97-98 \%$ respectively). Thus, the sample of these three sequences belongs to $C$. angulata (Fig. 3). 


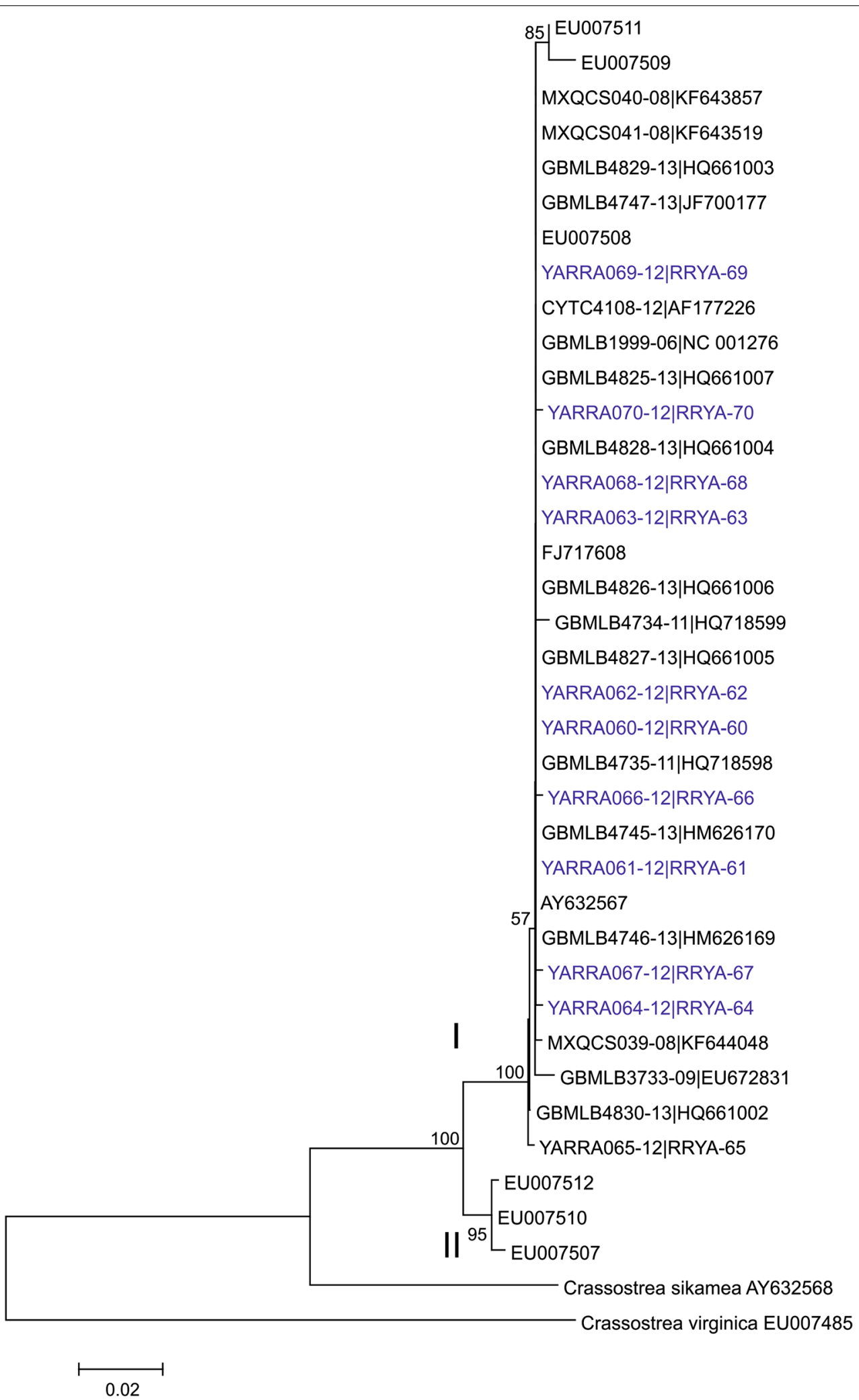

Fig. 2 Neighbor-joining (NJ) phylogram generated from COI data within the Pacific oyster Crassostrea gigas (the length of sequences is 642 bp) (first dataset). Numbers above or below the branches are NJ bootstrap 


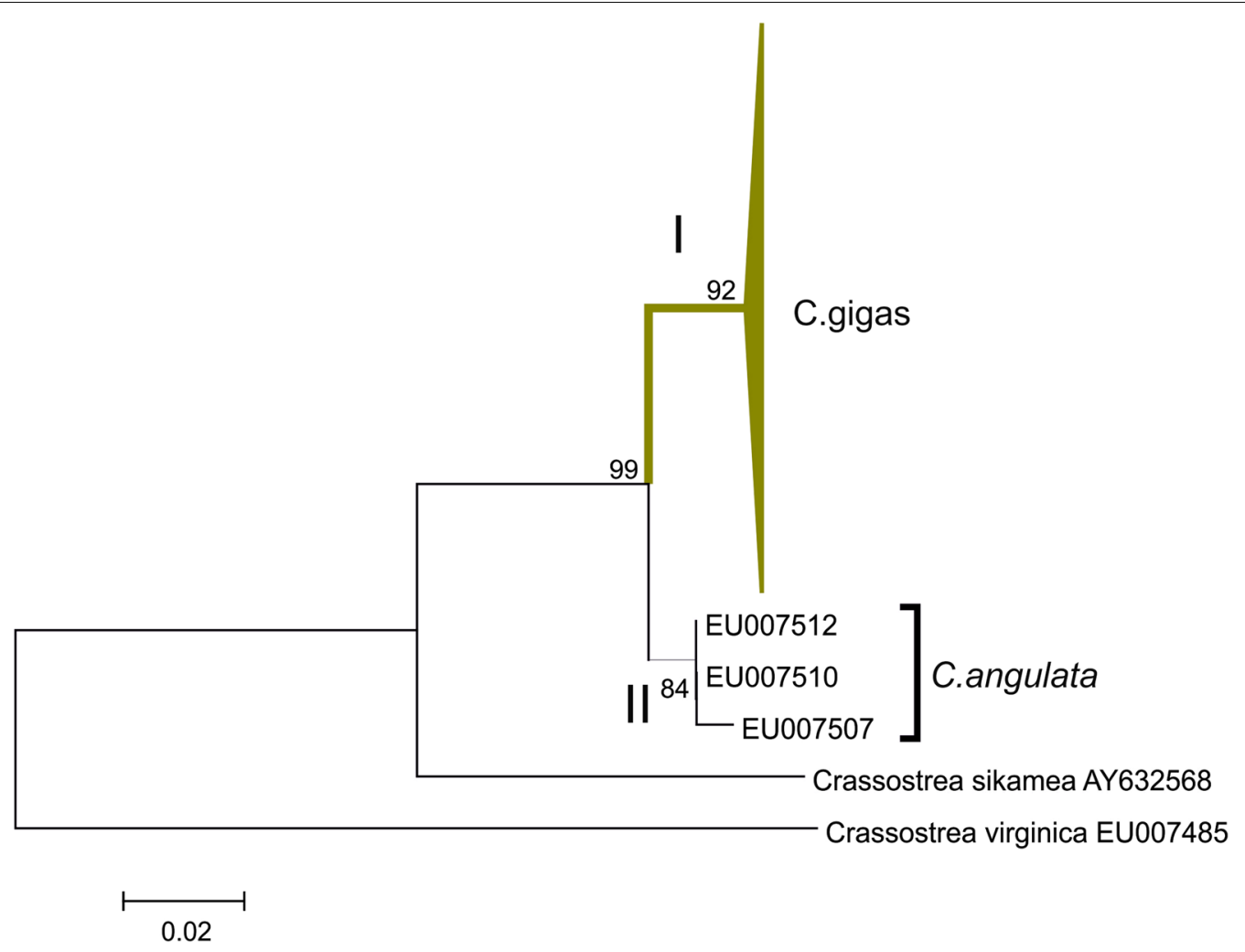

Fig. 3 Neighbor-joining (NJ) tree analysis of the COI sequences for the Pacific oyster Crassostrea gigas (the length of sequences 345 bp) (second dataset). Numbers above or below the branches are bootstrap values of the NJ analysis

Clade I consists of the most specimens that were chosen from the databases and also includes our data. All individuals collected by us showed low interspecific divergence for the COI gene (Fig. 2). Thus, these data allow to define our specimens as C. gigas.

\section{Intraspecific sperm morphology by TEM}

At low magnification, the sperms of $C$. gigas collected from the four localities of the Peter the Great Bay appear similar, having compact heads tailed with thin flagella (Fig. 4A-D). Our TEM analysis using random projections of ultrathin sections also showed that the sperm of C. gigas sampled from four sea areas generally had a similar structure. This structure is featured with a barrel-shaped head composed of a cup-like acrosome and electron-dense nucleus (Fig. 4E-H). Some projections showed a flagellum protruding from the head (Fig. 4E). However, most projections did not show a flagellum (Fig. 4F-H). Each sperm head normally has a periacrosomal area where there is a space between the acrosome and nucleus (Fig. 4E). Some projections showed an axial rod contained in the periacrosomal area (Fig. 4F). However, in most cases, an axial rod is not seen in periacrosomal areas (Fig. 4E, G, H).
Based on anterior-posterior projections found in sperm sections, we determined that both the flagellum and axial rod are typical structures of C. gigas sperms in Primorye. An axial rod is situated between the basal part of the acrosome and the bottom part of the anterior nuclear fossa. The midpiece contain mitochondria. Using cross sections, we were able to discriminate four mitochondria (not shown). The intermitochondrial space contains the centrioles. The proximal centriole lies in close proximity to the posterior nuclear fossa. This centriole contacts the posterior nuclear fossa by pericentriolar projection. The distal centriole is the basal body of the flagellum (Fig. 4I-K).

At least three sperm morphs could be discriminated based on the ultrastructure of their acrosomes. These were the sperms with a two-level acrosome with an apical acrosomal knob (Fig. 4I), the sperm with a twolevel acrosome without an apical knob (Fig. 4J), and the sperm with a platelet-like acrosome (Fig. 4K). The mitochondria could have both a round shape (Fig. 4I, $\mathrm{K})$ and an elongated shape (Fig. 4J). 

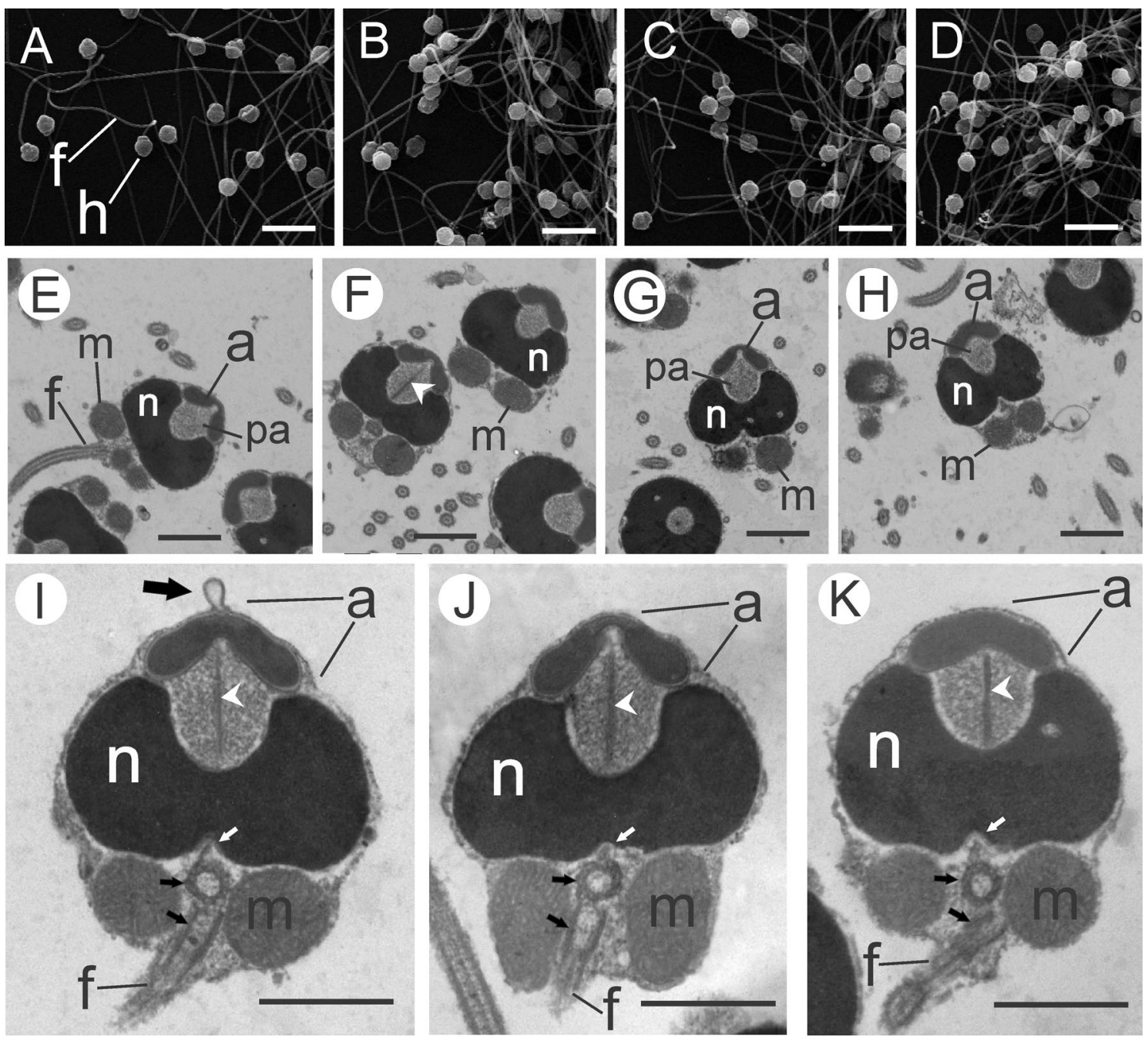

Fig. 4 The Pacific oyster Crassostrea gigas sperm by scanning electron microscopy (SEM) and transmission electron microscopy (TEM). A-D The low magnification of sperm sampled from C. gigas collected in Amursky Bay (A), Eastern Bosphorus Strait (B), Ussuriisky Bay (C) and Vostok Bay (D) by SEM; note the head (h) and flagellum (f) that normally constitute sperm cells. E-H The random projections of the sperm sampled from C. gigas collected in Amursky Bay (E), Eastern Bosphorus Strait (F), Ussuriisky Bay $(\mathbf{G})$ and Vostok Bay $(\mathbf{H})$ by TEM; note the flagellum (f) (E), nucleus $(\mathrm{n})$, mitochondrion (m), acrosome (a) and periacrosomal area (pa) that normally constitute sperm cells (E-H); the arrowhead shows the axial rod that could be occasionally seen in the periacrosomal area at some projections $(\mathbf{F})$. I-K The anterior-posterior sperm section projections showing typical intraspecific variations by TEM. Note the sperms having a two-level acrosome (a) with an apical acrosomal knob (large arrow) (I), the sperm having a two-level acrosome (a) without an apical knob (J), and the sperm with a platelet-like acrosome (a) (K); note the round (I, K) and elongated (J) mitochondria (m); note that the sperm features that are similar in the three images (I-K) include the barrel-shape nucleus (n), the axial rod (arrowheads) located in the periacrosomal areas, a proximal centriole (top black arrows) having a projection that contacts a nucleus in the area of posterior nuclear fossa (white arrows) and a distal centriole (bottom black arrows) acting as a basal body of the flagellum (f). Scale bar-10 $\mu \mathrm{m}$ (A-D), $1 \mu \mathrm{m}(\mathbf{E}-\mathbf{K})$

\section{Intraspecific sperm morphology by SEM}

By SEM we determined that in four localities of the Peter the Great Bay, C. gigas is characterised by six sperm morphs that are regularly repeated in each oyster collection: (1) sperm with a two-level acrosome with an apical acrosomal knob and a wide mitochondrial area (Fig. 5A), (2) sperm with a two-level acrosome with an acrosomal knob and a narrow mitochondrial area (Fig. 5B), (3) sperm with a two-level acrosome without an apical knob and with a wide mitochondrial area (Fig. 5C), (4) sperm with a two-level acrosome without an apical knob and with a narrow mitochondrial area (Fig. 5D), (5) sperm with a platelet-like acrosome (Fig. 5E), and (6) sperm with a non-central platelet-like acrosome (Fig. 5F).

Quantification showed that proportions of sperm patterns differed depending on location. Location 1 (Fig. 1), 

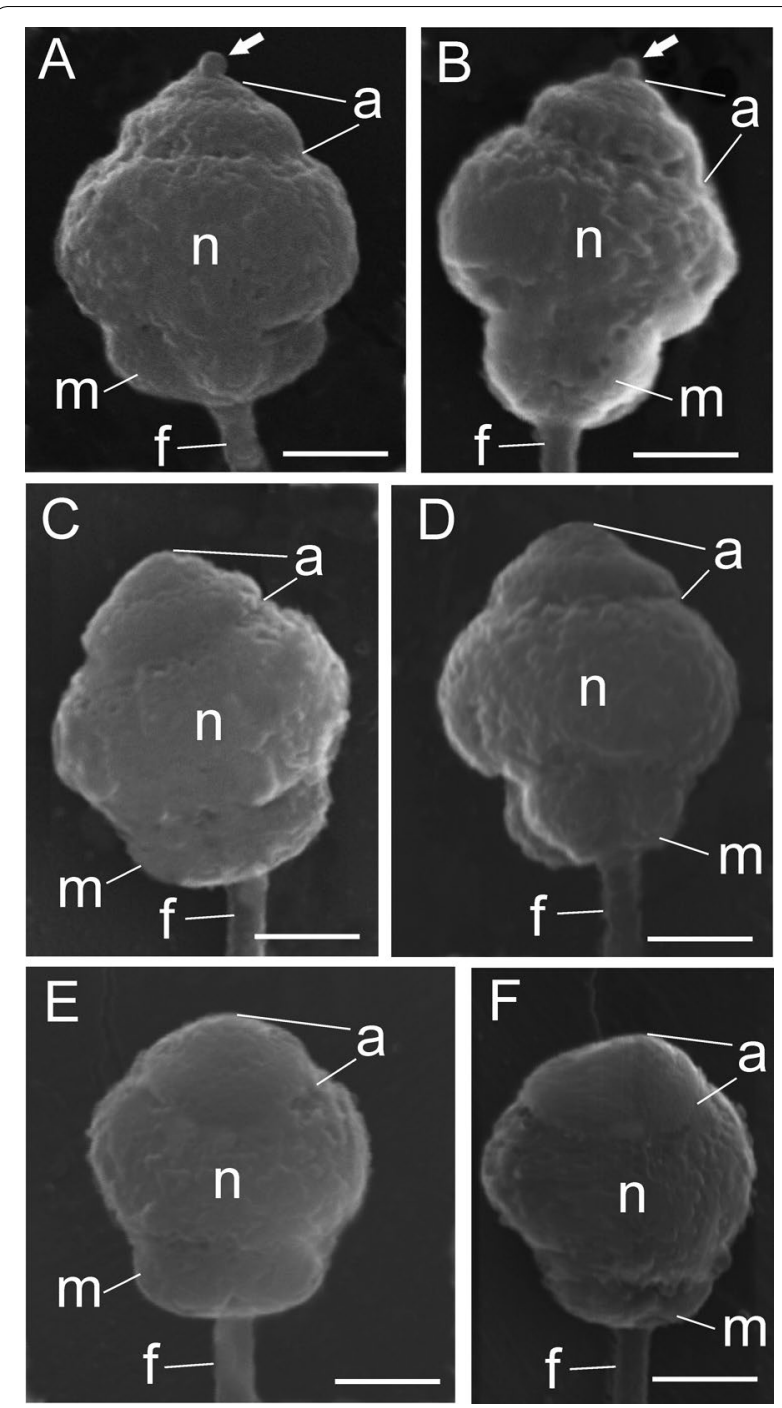

Fig. 5 The morphologies of the Pacific oyster Crassostrea gigas sperm by scanning electron microscopy. A The sperm have a two-level acrosome with an apical knob and a wide mitochondrial area; $\mathbf{B}$ the sperm have a two-level acrosome with an apical knob and a narrow mitochondrial area; $\mathbf{C}$ the sperm have a two-level acrosome without an apical knob and with a wide mitochondrial area; $\mathbf{D}$ the sperm have a two-level acrosome without an apical knob and with a narrow mitochondrial area; $\mathbf{E}$ the sperm have a platelet-like acrosome; $\mathbf{F}$ the sperm have a non-central platelet-like acrosome. A-F Respectively correspond to 1-6 for diagrams $6 a-d$. Arrows show the apical knob; a acrosome; $n$ nucleus; $m$ mitochondrial area; $f$ flagellum. Scale bar-1 $\mu \mathrm{m}$

Amursky Bay, was characterised by the presence of five abundant sperm morphs (more than 10\% for each morph) and the sixth morph in minor quantities (Fig. 6a). In location 2 (Fig. 1), a peninsula situated in the Eastern Bosphorus Strait, only one pattern was abundant, although the other five were present in minor quantities (Fig. 6b). Three abundant sperm morphs were typical
(Fig. 6c) for oysters in location 3, Ussuriisky Bay (Fig. 1). Location 4 (Fig. 1), Vostok Bay, where all six sperm morphs were abundant (Fig. 6d).

\section{Discussion}

Recently, the species name of oyster Crassostrea gigas has been changed to Magallana gigas [16]. Taking into account that the renaming was objected by 27 scientists and is urged to be reconsidered [17], the genus change does not seem final. Prior to a final decision being achieved by scientific community, we prefer to follow the traditional name of this mollusc-C. gigas.

Using COI DNA barcoding, we highlighted that the wild oyster collected in four localities of Primorye belongs to $C$. gigas. We also tested if sperms of $C$. gigas would help discriminate this oyster from other Ostreidae. We found that in each locality of the Peter the Great Bay the sperms of $C$. gigas appear with compact heads tailed with thin flagella, and hence correspond to "primitive spermatozoa", known to be well adapted for external fertilisation in sea water [18-20].

Previous data concerning the oysters' male gametes has been mostly obtained by TEM. Interspecific similarity of sperm ultrastructure was registered by this method in several reports [21-26]. Some authors speculated that minor intra-sperm differences may be used as interspecific signs to discriminate the oyster species [26, 27]. Since the data appears controversial, more detailed research seemed necessary to clarify if species specific traits could be found in oyster spermatozoa. Therefore, here, we focused on an in-depth study of C. gigas sperm to find out if its structure is similar or different regarding sperm of other oyster species previously described in the literature.

Our own results obtained by TEM were not definitive. On the one hand, the ultrastructural features of $C$. gigas habituating in the Peter the Great Bay are more likely typical for common oyster sperm patterns [28, 29]. On the other hand, a study of the anterior-posterior sperm head projections enabled discrimination of at least three morphs based on the ultrastructure of acrosomes. Based on TEM images, we have suggested that intraspecific sperm variation exists in $C$. gigas habituating in Primorye.

However, due to the randomness of the anterior-posterior projection finding, as well as restricted spatial possibility of the ultrathin sections, we could not guarantee convincing quantitative analyses of sperm morphs using TEM only. Taking into account that interesting results concerning interspecific and intraspecific differences have been obtained by studying the external morphology of male gametes [30-33], we also investigated sperm exteriors using SEM. Surprisingly, as shown above, we 


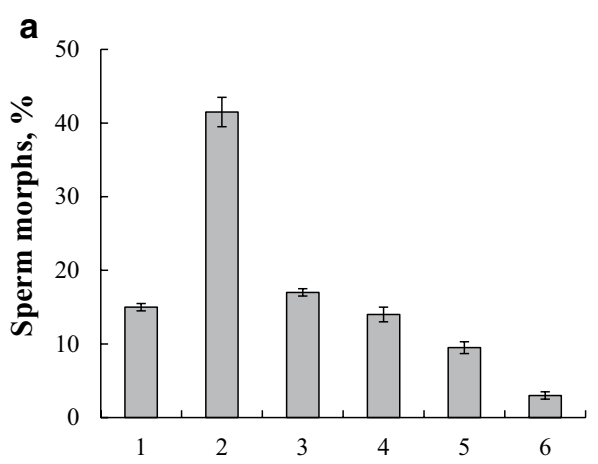

b

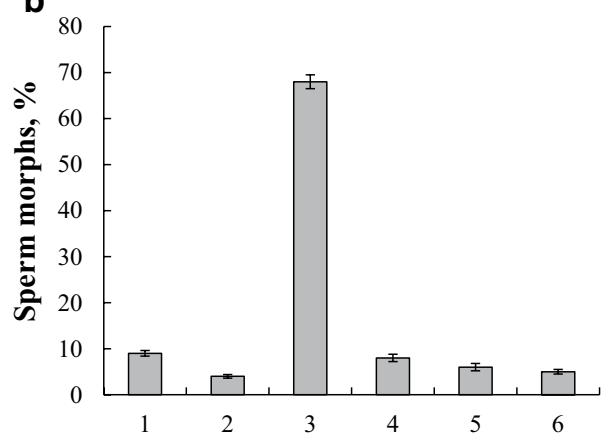

C

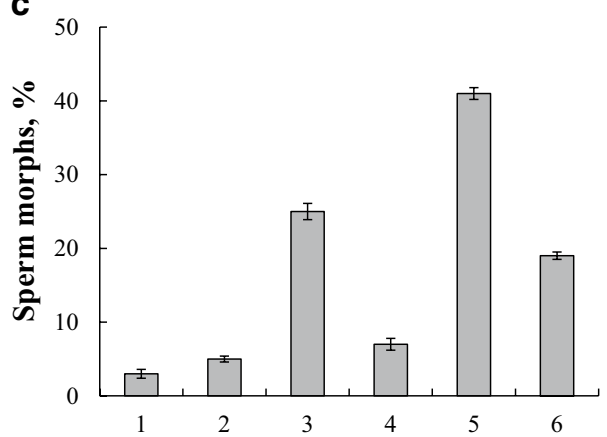

d

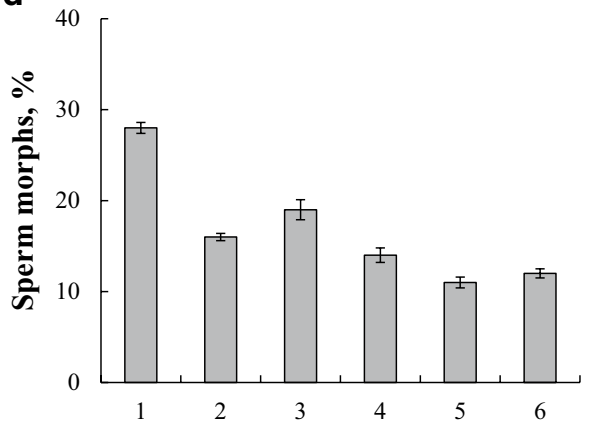

Fig. 6 Pacific oyster Crassostrea gigas. The diagrams show the proportions of sperm morphs that are characteristic for different geographic locations of Primorye. a Amursky Bay; b Eastern Bosphorus Strait; c Ussuriisky Bay; d Vostok Bay. Sperm morphs 1-6 correspond to Fig. 5a-f respectively found six regularly repeated sperm morphs that were normally produced by testes of each sample collected.

The heteromorphy is a characteristic species specific feature of the C. gigas sperm in Primorye. Unfortunately, based on the data published, we were unable to find any other reports concerning sperm heteromorphy in Ostreidae. Therefore, we could not determine if the heterogeneity of sperm is a unique feature of C. gigas in Primorye or if the same phenomenon exists for $C$. gigas habituating other locations and for other oyster species. Further work will be needed to test if sperm plasticity could exist in other oysters. Answering this question is crucial to finding out if an interspecific comparison based on sperm morphology could be effective in Ostreidae.

Sperm plasticity may be assigned to environmental factors The sperm plasticity found in C. gigas is not an exceptional phenomenon. Intraspecific variations distinct from any abnormal sperm types but related to heterogeneity of normal gametes is a usual feature described in both invertebrates and vertebrates [31, 34-36]. In marine invertebrates, intraspecific sperm variability has been discovered as a phenomenon concomitant to reproductive character displacement that entails genetic divergence of species [30, 37, 38]. Environmental factors could also influence sperm morphology [35]. Taking into account that oyster morphological plasticity is tightly connected to environmental conditions [9], the reasons for plasticity of oyster sperm might also be related to environmental factors.

It should be stressed that in Primorye the geographical locations are unique regarding the ecological conditions. Location 1, Amursky Bay, is highly contaminated due to the inflow of sewage from industrial areas. Pollution affects the physiological conditions of the bottom marine organisms in this geographical area $[39,40]$. The poor physiological condition of males is usually accompanied by raising more sperm morphs [32]. The five abundant sperm morphs (more than 10\% for each morph) were found in this area. The sixth pattern appears very minor and does not belong to the abundant morphs. It could be suggested that the presence of so many abundant sperm morphs is a result of a poor physiological oyster state induced by the permanent effects of chemical contaminations.

Location 2 is a peninsula situated in the Eastern Bosphorus Strait between the island and continent. This area undergoes a constant inflow of water, having no contamination and very stable temperature, salinity and current intensity [40, 41]. We found that oysters collected from this location have only one abundant sperm pattern although the other five are present in minor quantities. It could be proposed that the dominance of only one sperm 
morph may be connected to the normal physiological state of the oysters living in a stable environment.

Location 3 is in Ussuriisky Bay. The environmental conditions lack any serious contamination and are described as relatively stable for the bivalve molluscs' life $[1,2]$. However, the oyster collection was performed in the shore area that undergoes constant and strong surf. Intensive water turbulence is a characteristic feature of this area. The turbulent water movement can reduce the probability of reproductive success during external fertilisation [42]. Therefore, the sperm variations could be necessary to increase the fertilisation probability in these difficult conditions. Some sperm has higher speeds and shorter longevity, and some are slower but have higher longevity [43]. It seems possible that the three abundant sperm morphs typical for the oysters living in this area might have been adopted to cope with variation of water turbulence.

Location 4, is in Vostok Bay, situated far away from the industrial areas and is relatively independent regarding antropogenic activity [44]. However, it is characterised by a very unstable natural environment. The temperature and salinity undergo frequent changes defined by the flowing of streams that impound the bay due to rains and exchange with the open part of the Peter the Great Bay $[40,45]$. C. gigas inhabiting this area produce six abundant sperm morphs. It seems likely that the maximum amount of abundant sperm morphs is connected to the very stressful environment of this location.

After investigating the oyster sperms in four geographical locations of Primorye, it seems possible that the amount of abundant sperm patterns is lower in locations with the most stable environments. A larger amount of abundant sperm patterns is typical for locations that are affected by a stronger influence of anthropogenic or natural factors. We suggest that the increase of the abundant morph variants may help to provide reproductive success of $C$. gigas during fertilisation in extreme aquatic conditions. Also, it should be stressed that there is a dominant sperm pattern that is most common in each of four studied geographical location of C. gigas in Primorye (Fig. 7a-d). Probably each of these morphs is most adapted to the specific environment of the corresponding location.

\section{Sperm plasticity is a choice from six morphs}

It is noteworthy that, regardless of the extreme conditions increasing the amount of abundant sperm patterns, the general amount of oyster sperm morphs never exceeded six patterns. Probably, these morphologically stable variants are genetically determined. This finding is consonant with the data of Moy et al. [46] who described the diversity of reproductive protein (bindin) isoforms in the sperm's acrosomes in C. gigas. The amount of sperm morphs (six) found by us in Pacific oyster is comparable to the amount of bindins (five) discovered for this species. The oyster's sperms contain bindin proteins of 35 , 48, 63, 75 and $88 \mathrm{kDa}$. Besides, the formation of more bindin variations is possible due to recombination and splicing of the bindin gene [46]. It seems reasonable to suggest that specific bindin isoforms may correspond to definite oyster sperm morphs. This hypothesis could be checked using immunomicroscopy.

\section{Practical implications from the study of C. gigas in Primorye}

It seems possible that the assesment of sperm plasticity characteristic for local oysters might be considered
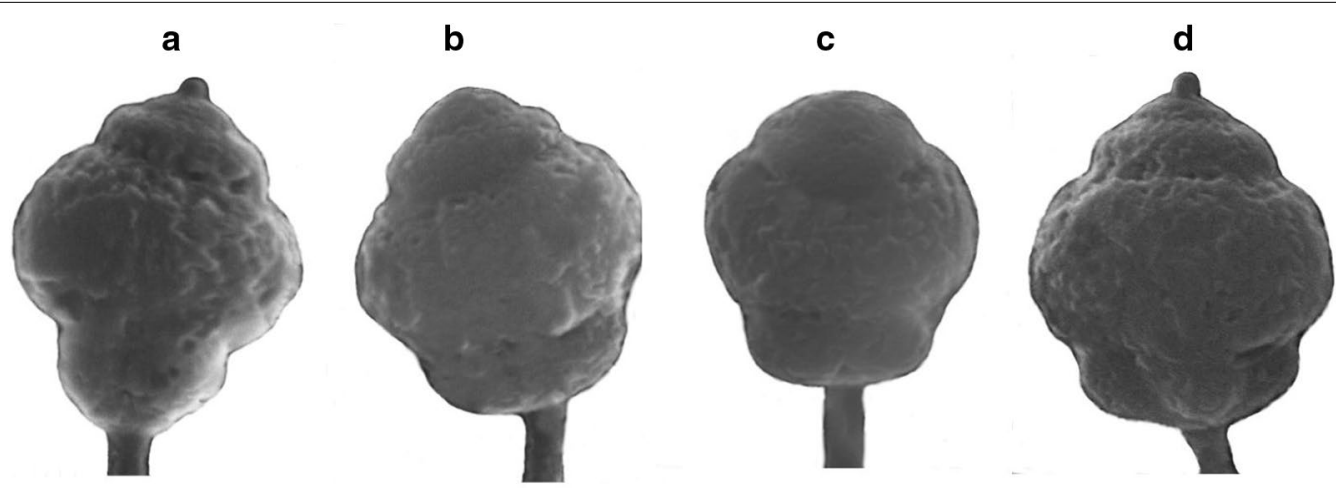

Fig. 7 Geographically assigned intraspecific sperm morphs typical for the Pacific oyster Crassostrea gigas in Primorye. a Sperm morph that is typical for the C. gigas in the Amursky Bay, b sperm morph that is typical for the C. gigas in the Eastern Bosphorus Strait, c sperm morph that is typical for the C. gigas in the Ussuriisky Bay, d sperm morph that is typical for the C. gigas in the Vostok Bay. Scale bar-1 $\mu m$ 
as a possible biomarker of ecological monitoring of the marine areas targeted for farming. Indeed, lower or larger amounts of abundant sperm morphs in the testing samples may help to assess if a water area is comfortable or stressful for potential oyster plantation. Also, taking into account that only one sperm pattern is dominant in each geographical location, oyster intraspecies geoauthentification seems possible. Indeed, globalisation of the food supply in the world, and the growing complexity of the supply chains made it difficult to trace the origin of seafood. The methods of evidence that the product originates in the area are very valuable in this regard [47]. Identification of the dominant sperm pattern could help identify the oysters' geographical origin. The supplement of mature testes preserved by fixation in alcohol or formalin followed by their testing in electron microscopy lab may be recommended for oyster producers.

\section{Conclusions}

The Primorye Pacific oyster C. gigas (for which the species validity was confirmed by a COI DNA barcoding test) is peculiar in having a heteromorphic sperm set that is composed of six morphologically stable patterns. Sperm heterogeneity precludes singular sperm pattern use as a species marker. The amounts of abundant sperm morphs (more than 10\% for each morph) are higher in the molluscs habituating risky environments and lower in ecologically favourable locations. We suggest that a higher amount of abundant sperm morphs provides reproductive success for oysters living in ecologically difficult aquatic areas. Only one sperm morph is the most common in each geographical locality and these typical morphs differ between localities. Ecological monitoring of the marine areas and commercially assigned intraspecific geo-authentification of $C$. gigas seem possible using heterogenic sperms.

\section{Abbreviations \\ COl: mitochondrial cytochrome oxidase I; TEM: transmission electron micros- copy; SEM: scanning electron microscopy.}

\section{Authors' contributions}

AR designed the study and was a major contributor in writing the manuscript. EV performed analysis by scanning electron microscopy. EZ performed part of the genetic analysis. YR performed sampling for genetic analysis and performed quantitative analysis. YA collected samples and performed part of the microscopy analysis. SS performed part of the genetic analysis. AA participated in study design, gave useful comments concerning the manuscript and participated in writing. All authors read and approved the final manuscript.

\section{Author details}

${ }^{1}$ Electron Microscopy Laboratory, University of Ottawa Heart Institute, 40 Ruskin St., Ottawa, ON K1Y 4W7, Canada. ${ }^{2}$ National Scientific Centre of Marine Biology, Far Eastern Branch of Russian Academy of Sciences, Vladivostok, Russia. ${ }^{3}$ Canadian Centre for DNA Barcoding, Biodiversity Institute of Ontario, Guelph, Canada. ${ }^{4}$ Far Eastern Federal University, Vladivostok, Russia.

\section{Acknowledgements}

We are deeply indebted to Mr. D.F. Fomin (National Scientific Centre of Marine Biology, Far Eastern Branch of Russian Academy of Sciences, Vladivostok, Russia) for the helpful assistance during our observations with the scanning electron microscope. The DNA barcoding analysis was implemented in the Canadian Centre for DNA Barcoding, Biodiversity Institute of Ontario, University of Guelph, Guelph, ON, Canada). Our gratitude to Irina Reunova-a student of St. Joseph Catholic High School (Ottawa, Canada)_for accurate proofing of English language and critical reading of this manuscript.

\section{Competing interests}

The authors declare that they have no competing interests.

\section{Availability of data and materials}

The datasets generated and analysed during the current study are available from the corresponding author on request, and will be available in ResearchGate after publication of the article.

\section{Consent for publication}

Written informed consent was obtained from study participants for participation in the study and for publication of this report and any accompanying images.

Ethics approval and consent to participate

Collection was performed under appropriate collection protocols.

Funding

This study was supported by the programme for fundamental research "The Far East", Project No. 15-I-6-007_o.

\section{Publisher's Note}

Springer Nature remains neutral with regard to jurisdictional claims in published maps and institutional affiliations.

Received: 3 January 2018 Accepted: 28 May 2018

Published online: 06 June 2018

\section{References}

1. Lutaenko KA. Bivalve molluscs of Ussuriysky bay (Sea of Japan). Part 1. Bull Rus Far East Mal Soc. 2005;9:59-81.

2. Lutaenko KA. Bivalve mollusks of Ussuriysky Bay (Sea of Japan). Part 2. Bull Rus Far East Mal Soc. 2006;10:46-66.

3. Lutaenko KA, Volvenko IE. Atlas of common bivalve mollusks of Peter The Great Bay (Sea of Japan). Vladivostok: Far Eastern Federal University; 2017.

4. Salvi D, Macali A, Mariottini P. Molecular phylogenetics and systematic of the bivalve family ostreidae based on rRNA sequence-structure models and multilocus species tree. PLoS ONE. 2014;9(9):e108696.

5. Hamaguchi M, Manabe M, Kajihara N, Shimabukoro H, Yamada Y, Nishi E. DNA barcoding of flat oyster species reveals the presence of Ostrea stentina Payraudeau, 1826 (Bivalvia: Ostreidae) in Japan. Mar Biodivers Rec. 2017;10:4. https://doi.org/10.1186/s41200-016-0105-7.

6. Will KW, Mishler BD, Wheeller QD. The perils of DNA barcoding and the need for integrative taxonomy. Syst Biol. 2005;54:844-51.

7. Son PW, Chung JS, Kim JH, Kim SH, Chung E-Y. Spermiogenesis and taxonomical values of sperm ultrastructures in male Crassostrea ariakensis (Fujita \& Wakiya, 1929) (Pteroirmorphia: Ostreidae) in the Estuary of the Seomjin River, Korea. Dev Reprod. 2014;18(3):179-86.

8. Hebert PDN, Cywinska A, Ball SL, DeWaard JR. Biological identifications through DNA barcodes. Proc R Soc Lon B Biol Sci. 2003;270:313-21.

9. Trivedi S, Aloufi AA, Ansari AA, Ghosh SK. Molecular phylogeny of oysters belonging to the genus Crassostrea through DNA barcoding. J Ent Zool Stud. 2014;2(6):308-13.

10. Sambrook J, Fritsch EF, Maniatis T. Molecular cloning: a laboratory manual. New York: Cold Spring Harbor Laboratory Press; 1989.

11. Folmer $\mathrm{O}$, Black $M$, Hoeh W, Lutz R, Vrijenhoek R. DNA primers for amplification of mitochondrial cytochrome c oxidase subunit I from diverse metazoan invertebrates. Mol Mar Biol Biotech. 1994;3:294-9. 
12. Edgar RC. MUSCLE: multiple sequence alignment with high accuracy and high throughput. Nucleic Acids Res. 2004;32(5):1792-7.

13. Tamura K, Peterson D, Peterson N, Stecher G, Nei M, Kumar S. MEGA5: molecular evolutionary genetics analysis using maximum likelihood, evolutionary distance, and maximum parsimony methods. Mol Biol Evolut. 2011;28(10):2731-9.

14. Kimura MA. Simple method for estimating evolutionary rate of base substitutions through comparative studies of nucleotide sequences. J Mol Evolut. 1980;16:111-20.

15. Meyer CP, Paulay G. DNA barcoding: error rates based comprehensive sampling. PLoS Biol. 2005;3(12):2229-38.

16. Salvi D, Mariottini P. Molecular taxonomy in 2D: a novel ITS2 rRNA sequence-structure approach guides the description of the oysters' subfamily Saccostreinae and the genus Magallana (Bivalvia: Ostreidae). Zool J Linn Soc. 2016;179(2):263-76.

17. Bayne BL, Ahrens M, Allen SK, D'Auriac AM, Backeljau T, Beninger P, Bohn R, Boudry P, Davis J, Green T, Guo X, Hedgecock D, Ibarra A, KingsleySmith P, Krause M, Langdon C, Lapegue S, Li C, Mahnahan D, Mann R, Perez-Paralle L, Powell EN, Rawson PD, Speiser D, Sanchez JL, Shumway S, Wang $\mathrm{H}$. The proposed dropping of the genus Crassostrea for all Pacific cupped oysters and its replacement by a new genus Magallana: a dissenting view. J Shellfish Res. 2017;36:545-7.

18. Franzén Å. Comparative morphological investigations into the spermatogenesis among Mollusca. Zool Bidr Upps. 1955;30:399-456.

19. Franzén Å. On spermatogenesis, morphology of the spermatozoon and biology of fertilization among invertebrates. Zool Bidr Upps. 1956:31:355-482.

20. Baccetti B, Afzelius BA. The biology of the sperm cell. Basel: New York: S. Karger; 1976

21. Daniels EW, Longwell AC, MCNiff JM. Ultrastructure of spermatozoa from the American oyster Crassostrea virginica. Trans Am Microsc Soc. 1971;90:275-82.

22. Healy JM, Lester RJG. Sperm ultrastructure in the Australian oyster Saccostrea commercialis (Iredale \& Roughley) (Bivalvia: Osteroidea). J Molluscan Stud. 1991;57:219-24.

23. Bozzo MG, Ribes E, Sagrista E, Poquet M, Durfort M. Fine structure of the spermatozoa of Crassostrea gigas (Mollusca, Bivalvia). Mol Reprod Dev. 1993;34:206-11.

24. Sousa M, Oliveira E. An ultrastructural study of Crassostrea angulata (Mollusca, Bivalvia) spermatogenesis. Mar Biol. 1994;120:545-51.

25. Eckelbarger KJ, Davis CV. Ultrastructure of the gonad and gametogenesis in the eastern oyster, Crassostrea virginica. II. Testis and spermatogenesis. Mar Biol. 1996;127:89-96.

26. Gwo JC, Liou CH, Cheng CH. Ultrastructure of the spermatozoa of the pacific oyster Crassostrea gigas (Mollusca, Bivalvia, Ostreidae). J Submicrosc Cytol Pathol. 1996;28:395-400.

27. Yurchenko OV. Comparative ultrastructural study of spermatozoa in some oyster species from the Asian-Pacific Coast. Micron. 2012;43:365-73.

28. Healy JM, Mikkelsen PM, Bieler R. Sperm ultrastructure in honeycomb (foam) oysters (Mollusca, Bivalvia, Gryphaeidae, Pycnodontinae): comparison with other Ostreoidea and taxonomic implications. Invertebr Biol. 2015;134:136-50.
29. Drozdov AL, Sharina SN, Tyurin SA. Sperm ultrastructure in representatives of six bivalve families from Peter the Great Bay, sea of Japan. Rus J Mar Biol. 2009;35:236-41.

30. Landry C, Geyer LB, Arakaki T, Uehara T, Palumbi SR. Recent speciation in the Indo-West Pacific: rapid evolution of gamete recognition and sperm morphology in cryptic species of sea urchin. Proc R Soc Lond B. 2003;270:1839-47.

31. Baer B, Schmid-Hempel P, Hoeg JT, Boomsma JJ. Sperm length, sperm storage and mating system characteristics in bumblebees. Insect Soc. 2003;50:101-8.

32. Schulte-Hostedde Al, Montgomerie R. Intraspecific variation in ejaculate traits of the northern watersnake (Nerodia sipedon). J Zool. 2006;270:147-52

33. Fitzpatrick JL, Montgomerie R, Desjardins JK, Stiver KA, Kolm N, Balshine $\mathrm{S}$. Female promiscuity promotes the evolution of faster sperm in cichlid fishes. PNAS. 2008;106(4):1128-32.

34. Morrow EH, Gage MJG. Consistent significant variation between individual males in spermatozoal morphometry. J Zool. 2001;254(2):147-53.

35. Pitnick SS, Hosken DJ, Birkhead TR. Sperm morphological diversity. In: Birkhead TR, Hosken DJ, Pitnick SS, editors. Sperm biology: an evolutionary perspective. Massachusetts: Academic Press; 2009. p. 69-150.

36. Vrech DE, Nime MF, Mattoni Cl, Peretti AV. Intra-male sperm variability: Is there heteromorphism in scorpions (Arachnida, Scorpions)? Zool Anz. 2016;261:12-21.

37. Arakaki Y, Uehara T. Morphological comparison of black Echinometra individuals among those in the Indo-West pacific. Zool Sci. 1999;16:551-8.

38. Geyer LB, Palumbi SR. Reproductive character displacement and the genetic of gamete recognition in tropical sea urchins. Evolution. 2003:57(5):1049-60.

39. Vaschenko MA, Zhadan PM, Almyashova TN, Kovalyova AL, Slinko EN. Assesment of the contamination level of bottom sediments of Amursky Bay (Sea of Japan) and their potential toxicity. Rus J Mar Biol. 2010;36(5):359-66.

40. Schornikov El, Zenina MA. Ostracods as indicators of conditions and dynamics of water ecosystems; on the example of Peter the Great bay, Sea of Japan. Vladivostok: Dalnauka; 2014.

41. Shver CA. Climate of the Vladivostok. Leningrad: Hydromedizdat; 1978.

42. Levitan D. Effects of gamete traits on fertilization in the sea and the evolution of sexual dimorphism. Nature. 1996;382(6587):153-5.

43. Levitan D. Sperm velocity and longevity trade off each other and influence fertilization in the sea urchin Lytechinus variegates. Proc R Soc Lond B. 2000:267:531-4.

44. Khristoforova NK, Zhuravel EV, Mironova YA. Recreational effects in Vostok Bay, sea of Japan. Rus J Mar Biol. 2002;28(4):274-7.

45. Stepanov VV. Characteristics of the temperature and salinity of the Vostok Bay of the Sea of Japan. Biological study of the Vostok bay: Vladivostok; 1976.

46. Moy GW, Springer SA, Adams SL, Swanson WJ, Vacquier VD. Extraordinary intraspecific diversity in oyster sperm bindin. PNAS. 2008;105(6):1993-8.

47. Serra R. European union policy for high quality agricultural products. In: Proceedings of the international symposium on geographical indications/Beijing, China, June 26-28, 2007. WIPO/GEO/BEI/07/WWW(81757).

Ready to submit your research? Choose BMC and benefit from

- fast, convenient online submission

- thorough peer review by experienced researchers in your field

- rapid publication on acceptance

- support for research data, including large and complex data types

- gold Open Access which fosters wider collaboration and increased citations

- maximum visibility for your research: over 100M website views per year

At BMC, research is always in progress.

Learn more biomedcentral.com/submissions 